\title{
Design and Analysis of 3D Scanning System for Scanning an Object
}

\author{
Mr. Aditya Gaykar, Ms. Advyta Jujaray, Ms. Shalmali Mutalik, Ms. Prachi Waghmode, Prof. Sanjay B Matekar \\ Mechanical Department \\ Pimpri Chinchwad College of Engineering \\ Pune, India
}

\begin{abstract}
D scanning is gaining its popularity in this newage technology, Industry 4.0 since it is the process of analysing a real-world object or environment to collect data on its shape and possibly its appearance. The collected data is then utilized to construct digital 3D models in CAD software. This technology is used in augmented reality, motion capture, gesture recognition, robotic mapping, industrial design, reverse engineering, prototyping, quality control, inspection and the digitization of cultural artifacts. This paper introduces a mechanism to construct a 3D scanner that is convenient to use and handle. The object held between two-point supports is scanned by Intel SR 300 laser scanner with the help of a dolly mechanism. Data points collected by the scanner are converted into an STL file in 3D Sense. These points can be imported and optimized using the Function Generative Design app of 3D Experience Platform, a Dassault Systeme's platform (3DPLM).
\end{abstract}

Keywords-3D Scanner, data points, reverse engineering, dolly mechanism, 3D modeling and Simulation.

\section{INTRODUCTION}

The first 3D scanning technology was produced in the 1960s and since then it has improved in terms of accuracy, time and effort.

The scanner is mounted on a dolly mechanism. This is a wheeled cart or similar device used in filmmaking and television production. A motorized dolly mechanism is used ensuring smooth motion and getting accurate points from the scanner.

The laser scanner calculates the time taken by laser from emission to the reception and the sensor gives geometrical information of the object. The distance of the object is calculated with the information of time.

The scope of this paper is to create a mechanism for a 3D scanner that scans any rigid object sizing between $50 \mathrm{~mm} x$ $50 \mathrm{~mm} \times 50 \mathrm{~mm}$ and $300 \mathrm{~mm} \times 300 \mathrm{~mm} \times 300 \mathrm{~mm}$.

\section{LITERATURE REVIEW}

Various 3D scanning methods suggest that to scan the object it should be held stationery and the camera should revolve around the object. After experimenting with the Intel 3D scanning camera, it is found that a speed of 1 RPM is optimum for scanning the object. The position of the camera plays an important role in scanning as the camera angles have to correct to scan the maximum area of the object. In a conference paper by Alaa Abd-Raheem, the author has proposed a mechanism for 3D scanning which involves the object being stationery and scanner rotating around it. This design however doesn't cover the base resting on the table while scanning the object. This drawback can be overcome by clamping the object at two points leaving rest of it exposed to the camera.

\section{A. Market survey}

There were few scanning mechanisms available in the market.

\section{1) First model}

The object to be scanned is held in between two-point supports. It is rotated about a vertical axis. The camera is placed stationary at the side with adjustable mounting. When the object is rotated the camera captures the surface of the object.

Advantage: More surface is exposed to the scanner.

Disadvantage: Difficult to rotate object between two pointers, due to inertia.

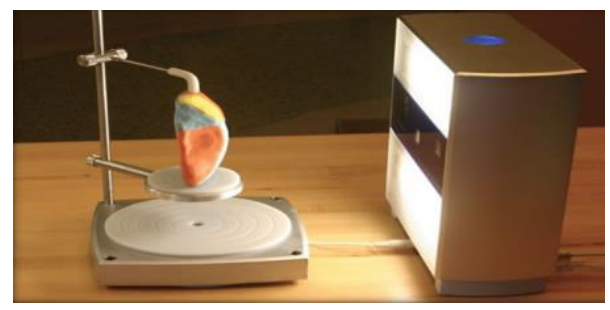

Figure 1 Model 1

\section{2) Second model}

The object to be scanned is kept stationary on a table. The camera has a mechanism to revolve around the object to scan the surface.

Advantage: Easy rotation of the camera.

Disadvantage: Cannot capture all the data points. As the object is mounted on the table, it is not possible to capture the lower data points of the body. There may be cavities or holes in the object at the lower part, which might be important to be captured 


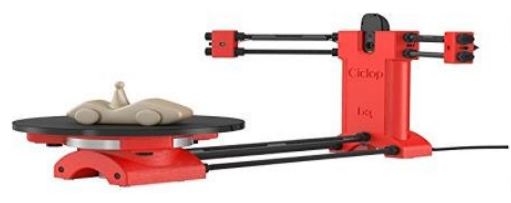

Figure 2 Model 2

\section{3) Third model}

This mechanism is a hybrid of the above mechanisms. It has the concept of supporting the object at two points from the first model and the concept of revolving the camera around the object kept stationary from the second mechanism. A dolly mechanism is introduced to revolve the camera in a circular track.

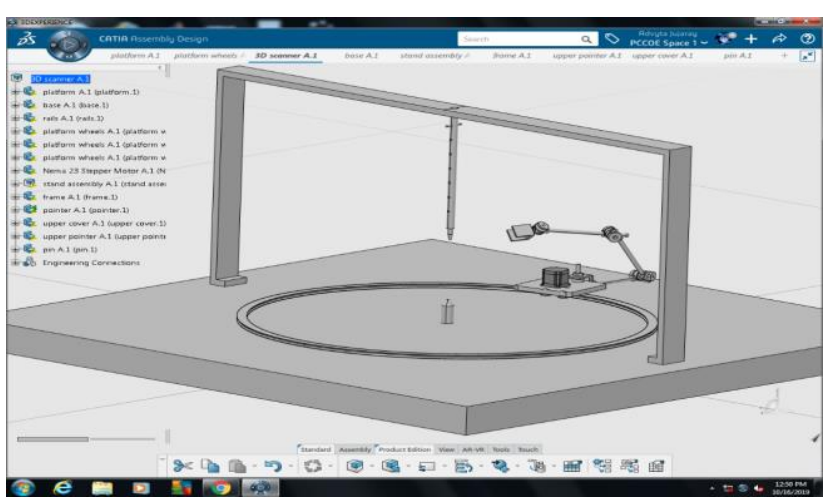

Figure 3 Model 3

\section{DESIGN CALCULATIONS}

Design calculations were done using the book Design of Machine Elements by V. B. Bhandari as reference.

The maximum size of the object $=30 \times 30 \times 30 \mathrm{cu} . \mathrm{cm}$. Considering maximum weight of the $300 \mathrm{~kg}$ i.e $\mathrm{F}=3 \mathrm{KN}$.

Material properties: (Design Data Book)

Material $=$ Fe620, E $=200 \mathrm{GPa}, \mathrm{S}_{\mathrm{yt}}=380 \mathrm{MPa}, \mathrm{S}_{\mathrm{ut}}=620$ $\mathrm{MPa}$

\section{A. Designing the lower pointer:}

The weight of the body scanned is supported on the lower pointer. Lower pointer is designed for Crushing,

$\sigma_{\mathrm{c}}=\frac{F}{\frac{\pi}{\mathrm{K}} \times d_{1}^{3}}$ (For crushing)

$\therefore d_{1} \approx 5 \mathrm{~mm}$

This is the minimum diameter of the lower pointer (support). This pointer is to be check for buckling.

\section{For frustum:}

To get the dimensions of the frustum Rankine's theory is utilized. Iterations are made assuming different dimensions of height and diameter of frustum and buckling load of the same is calculated. To find moment of inertia,

$\mathrm{d}_{1}=$ smaller diameter

$\mathrm{d}_{2}=$ Larger diameter

$\mathrm{h}_{1}=$ height of the frustrum part of the pointer

$\mathrm{h}_{2}=$ height of the cylindrical part of the pointer

$a_{1}=\frac{1}{2} \times\left(d_{1}+d_{2}\right) \times h_{1}$,

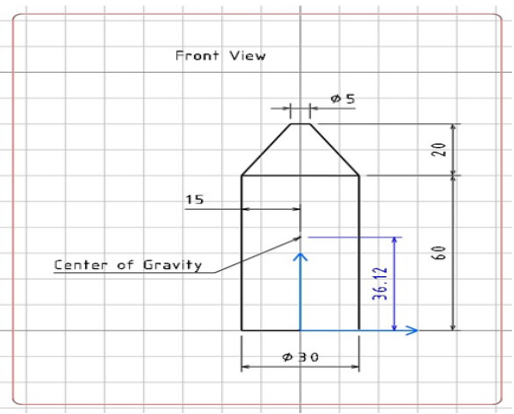

Figure 4 Lower Pointer

$a_{2}=h_{2} \times d_{2}$

$\mathrm{y}_{1}=\left(\frac{h_{1}}{3}\right)\left(\frac{d_{2}+2 d_{1}}{d_{2}+d_{1}}\right)+\mathrm{h}_{2}, \mathrm{y}_{2}=\frac{h_{2}}{2}$

$\bar{y}=\frac{a_{1} y_{1}+a_{n} y_{2}}{a_{1}+a_{n}}$

$\mathrm{I}_{\mathrm{xx} 1}=\frac{h_{1}^{\mathrm{a}}}{12} \times\left(3 d_{1}+d_{2}\right)$,

$\mathrm{I}_{\mathrm{yy} 1}=\frac{h_{1}}{3} \times\left(\frac{2 d 1+d 2}{d 1+d^{2}}\right)+\left(a_{1} \times l^{2}\right)$

Assuming dimensions for calculations,

\section{Iteration 1}

$\mathrm{d}_{2}=50 \mathrm{~mm}, \mathrm{~h}_{1}=10 \mathrm{~mm}, \mathrm{~h}_{2}=60 \mathrm{~mm}$

$\mathrm{P}_{\mathrm{r}}=\frac{\sigma_{c} \mathrm{~A}}{1+a\left(\frac{e_{e q}}{\tilde{k}}\right)^{2}}$

$\mathrm{P}_{\mathrm{r}}=822.17 \mathrm{kN}$

\section{Iteration 2}

$\mathrm{d}_{2}=30 \mathrm{~mm} \mathrm{~h}=20 \mathrm{~mm}, \mathrm{~h}_{2}=60 \mathrm{~mm}$

$\mathrm{P}_{\mathrm{r}}=537.7 \mathrm{kN}$

This is the maximum load to be applied to avoid buckling, which is greater than the actual maximum load applied $(3 \mathrm{kN})$. Hence, the design is safe from buckling.

Now, final dimensions are as follows,

$\mathrm{d}_{1}=5 \mathrm{~mm}, \mathrm{~d}_{2}=30 \mathrm{~mm}, \mathrm{~h}_{1}=20 \mathrm{~mm}, \mathrm{~h}_{2}=60 \mathrm{~mm}$

\section{B. Designing the outer flutes of the upper pointer:}

The upper pointer does not carry any load. It will fail only due to self-weight. Assuming outer diameter $\mathrm{d}_{0}=20 \mathrm{~mm}$ and thickness $=2 \mathrm{~mm}$, we get, $\mathrm{d}_{\mathrm{i}}=16 \mathrm{~mm}$

Load due to self-weight at highest point,

Mass $=$ Density $*$ Volume

Weight $=2.99 \mathrm{~N}=3 \mathrm{~N}$ 
The pointer may fail due to shear; hence it is designed for shearing.

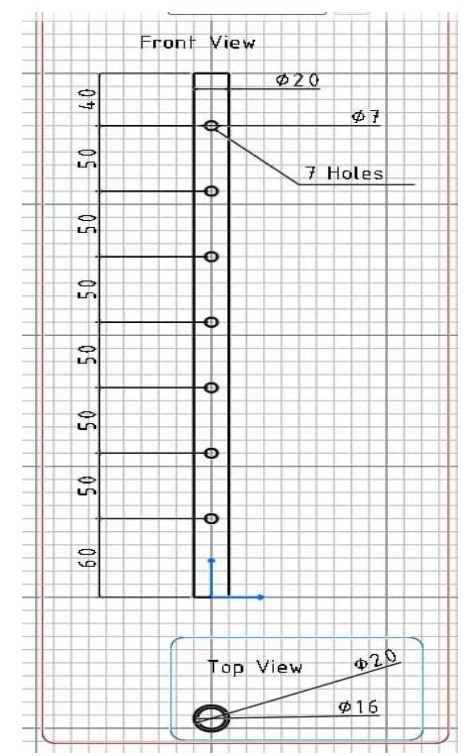

Figure 5 Upper outer flute

$$
\begin{aligned}
\tau & =\frac{0.5 \times s y t}{F \cap S} \\
& =95 \mathrm{MPa} \\
\tau & =\frac{P}{2 \times \frac{\pi}{4} \times d^{2}}
\end{aligned}
$$

$\mathrm{d} \approx 5 \mathrm{~mm}$

This is the minimum diameter required for the external flute. Hence, our assumed dimensions are safe.

Weight of the pointer $=10 \mathrm{~N}$ (negligible), Material: Fe620

Threading will be required at the bottom of the upper pointer and inner flute.

Pitch $=1 \mathrm{~mm}$, Outer diameter $\left(\mathrm{d}_{\mathrm{o}}\right)=20 \mathrm{~mm}$,

Thickness $(\mathrm{t})=2 \mathrm{~mm}$, Inner diameter $\left(\mathrm{d}_{\mathrm{i}}\right)=16 \mathrm{~mm}$

\section{Designing pin between the flutes:}

Total weight acting on the pointer is self-weight and clamping force applied. Therefore, weight $=10 \mathrm{~N}$. The pin will shear between the inner and outer flutes of the upper pointer. Assuming the diameter of the pin $=7 \mathrm{~mm}$, Total length of the pointer $\mathrm{L}=400 \mathrm{~mm}$.

\section{1) Design for shearing:}

$$
\begin{aligned}
\tau & =\frac{P}{2 \times \frac{I}{4} \times d^{2}} \\
& =0.1299 \mathrm{MPa}
\end{aligned}
$$

This is force is less than the actual applied shear force (95 $\mathrm{MPa})$, Hence design is safe.
D. Dimensions of the inner flute of the upper pointer:

Core diameter $\left(\mathrm{d}_{\mathrm{c}}\right)=15 \mathrm{~mm}$

7 holes of $7 \mathrm{~mm}$ diameter will be drilled on both inner and outer flute as shown in the figure.

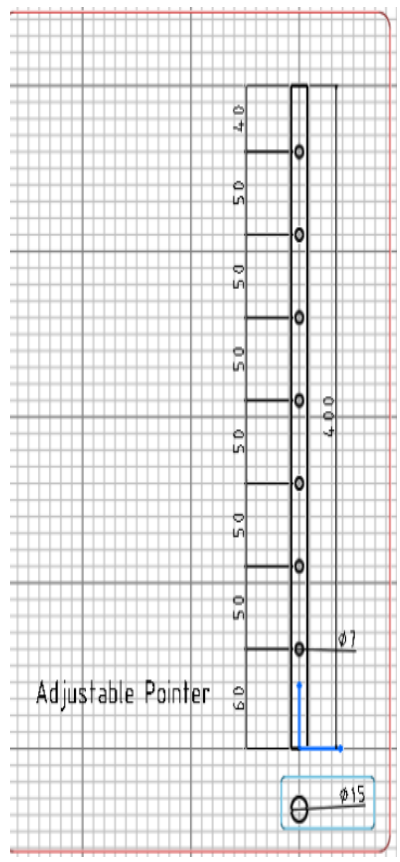

Figure 6 Upper Pointer

\section{E. Dimensions of the upper pointer:}

$\mathrm{d}_{1}=5 \mathrm{~mm}, \mathrm{~d}_{2}=12 \mathrm{~mm}, \mathrm{~h}_{1}=20 \mathrm{~mm}, \mathrm{~h}_{2}=60 \mathrm{~mm}$

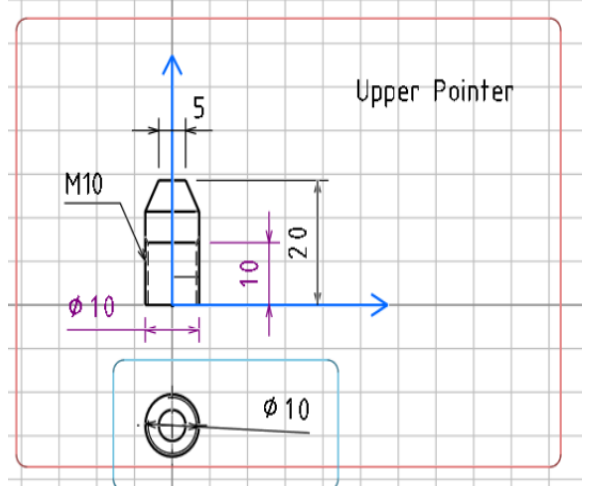

Figure 7 Upper pointer

The platform will rotate along the rails. It will carry the load of motor, camera(scanner), platform(itself) and the connecting rods. These components approximately weigh $10 \mathrm{~kg}$

$\therefore$ Weight $=100 \mathrm{~N}$

Thickness $=15 \mathrm{~mm}$

As per the scope of the project, the small object measures $=5 \times 5 \times 5$ cu.cm.

- For Small Object: 
The diameter of the rails is 1 meter. The maximum distance the camera will be placed away from the rails is $40 \mathrm{~cm}$. This distance will not exceed as the radius $(50 \mathrm{~cm})$ and the camera will be unable to scan the object which is near than $10 \mathrm{~cm}$. Hence, the moment will act on the rails in the inner side of the rail.

Inner moment $=400(\mathrm{~mm}) \times 100(\mathrm{~N})=40,000 \mathrm{Nmm}$

- For big Object:

When the object is of bigger size, the camera needs to be placed away from the rails. The maximum distance the camera will be placed away from the rails is $10 \mathrm{~cm}$

Moment $=100(\mathrm{~mm}) \times 100(\mathrm{~N})=10,000 \mathrm{Nmm}$

Carriage: $I_{x x}=\frac{1}{12} \times 15^{3}$ x $150=42187.5 \mathrm{~mm}^{4}$

$I_{\mathrm{yy}}=\frac{1}{12} \times 150^{3} \times 15=4218750 \mathrm{~mm}^{4}$

$\mathrm{I}=\mathrm{I}_{\mathrm{xx}}+\mathrm{I}_{\mathrm{yy}}$

$\mathrm{I}=42187.5+4218750=4260937.5 \mathrm{~mm}^{4}$

The frame is fixed so no moments and shearing occur. Dimensions: $150 \times 150 \times 15 \mathrm{~mm}^{3}$

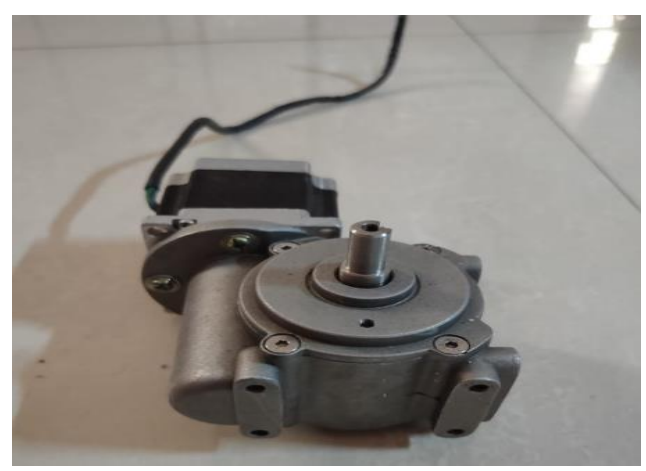

Figure 8 Stepper Motor

Power of Motor $\mathrm{P}=7$-Watt, Weight of system on carriage $=$ $5 \mathrm{Kg}$

$\mathrm{F}=5 \times 9.81=50 \mathrm{~N}$

Force on each Wheel $=\frac{F}{2}=25 \mathrm{~N}$

Assume $\mathrm{d}_{2}=0.05 \mathrm{~m}$, diameter of driving wheel. Now, using velocity ratio formula

$\frac{v_{1}}{v_{2}}=\frac{d_{1}}{d_{n}}-\frac{N_{2}}{N_{1}}$

$\mathrm{N}_{1}=$ Speed of carriage on rails

$\mathrm{N}_{2}=$ Speed of driving wheels

$\mathrm{N}_{3}=$ Speed of driven wheels

$\frac{1}{0.05}=\frac{N_{2}}{1}$

$\mathrm{N}_{2}=20 \mathrm{rpm}$

$\frac{d_{1}}{d d_{R}}=\frac{N_{2}}{N_{1}}$

\section{$\frac{1}{(5+2) \times 10^{-2}}=\frac{N_{3}}{1}$}

$2 \mathrm{~cm}$ extra is taken for rubber stopper. So, $N_{3}=15 \mathrm{rpm}$

\section{F. Designing Belt:}

Using basic power equation, $\mathrm{P}=\frac{2 \times \pi \times N \times F \times r}{6 n}$

$$
\begin{aligned}
& =\frac{2 \times \pi \times 20 \times 0.025}{6 n} \\
& =1.308 \mathrm{~W}
\end{aligned}
$$

Selection of Flat-belt from Manufacturer's Catalogue, the maximum power transmitted by belt $=(\mathrm{kW})_{\max }=\mathrm{F}_{\mathrm{a}} \times \mathrm{kW}$

Where, $(\mathrm{kW})_{\max }=$ power transmitted by the belt for design purpose

$\mathrm{kW}=$ actual power transmitted by the belt in a given application

$\mathrm{F}_{\mathrm{a}}=$ load correction factor

Now, load correction factor $F_{a}=1.2$ for steady load (e.g. centrifugal pumps, fans, light machines tools, conveyors)

Power transmitted by belt for design purpose $(\mathrm{kW})_{\max }$

$$
\begin{aligned}
& =1.2 \times 1.308 \\
& =1.5707 \mathrm{~W}
\end{aligned}
$$

The power transmitting capacities of belt are developed for $180^{\circ}$ of arc of contact. The actual arc of contact will be different in different in different applications. Angle of wrap for driving wheel, $\Theta=230^{\circ}$. Therefore, $F_{d}=0.86$ (from design data book)

$$
\begin{aligned}
\mathrm{kW}_{\text {corrected }} & =(\mathrm{kW})_{\max } \times \mathrm{F}_{\mathrm{d}} \\
\mathrm{kW}_{\text {corrected }} & =1.35 \mathrm{~W}
\end{aligned}
$$

HI-SPEED duck belting is selected for general purpose applications,

Corrected $\mathrm{kW}$ rating $=\frac{0.0118 \times v}{5 . n 8}=0.1216 \mathrm{~W}$

Now,

$$
\begin{aligned}
(\text { Width } \times \text { No of Plies }) & =\frac{k W_{\text {corrected }}}{\text { corrected } k W \text { rating of belt }} \\
& =\frac{1.35}{0.1216} \\
& =11.101
\end{aligned}
$$

Therefore, selecting No of plies $=3$ and width of belt $=7 \mathrm{~mm}$.

MODEL: The platform rotates on the rail, with the help of wheel. The wheel is connected to the motor, after giving power supply to the motor, the wheel rotates from the inner side of the rail. The outer side of rail is supported by two bearings, which is exactly opposite to the wheel placement. A belt runs over these two bearings and in this way the stand rotates smoothly. When the object is placed between two 
pointers, the upper flutes can be adjusted as per the object size. In this way, the complete system is brought to scan the object. The scanner rotates around the object and scans the necessary data points. A 3D Model was created using 3D Experience Platform for a better visualization and understanding using the dimensions of parts found after calculations.

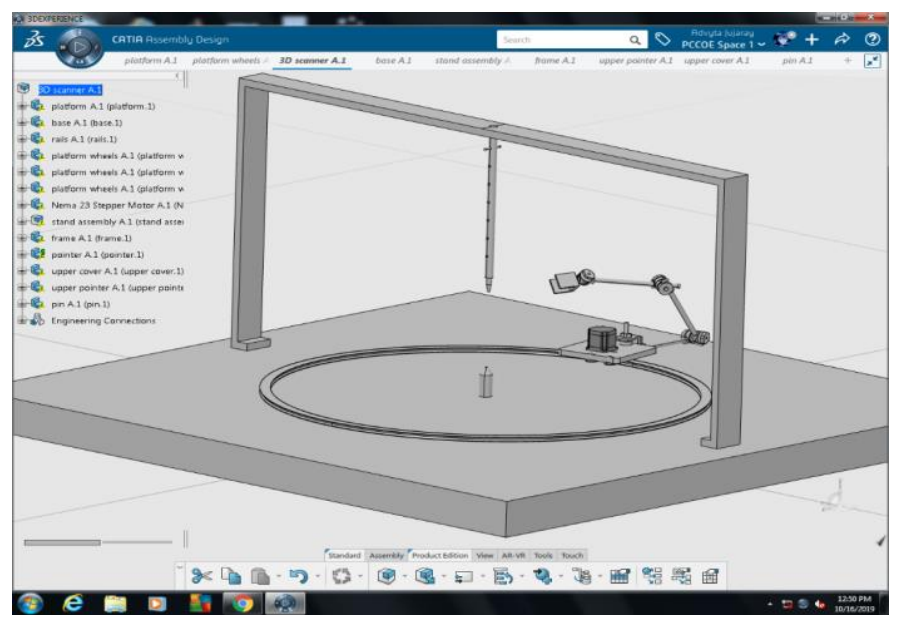

Figure 9 3D Model of the Mechanism

\section{ANALYSIS}

Analysis was carried out using 'Simulia' apps from 3D Experience software. The main apps used were

- Part Design

- Structural Scenario Creation

- Mechanical Scenario Creation

- Physics Results Explorer

As only the lower pointer will be under load, simulation was done for only that part. This pointer will only support the load of the object so, accordingly a mechanical scenario was created and results were explored.

\section{1) Outcome of Analysis}

After the analysis on the lower pointer was done it was found that stresses on the pointer were negligible and that the design was safe

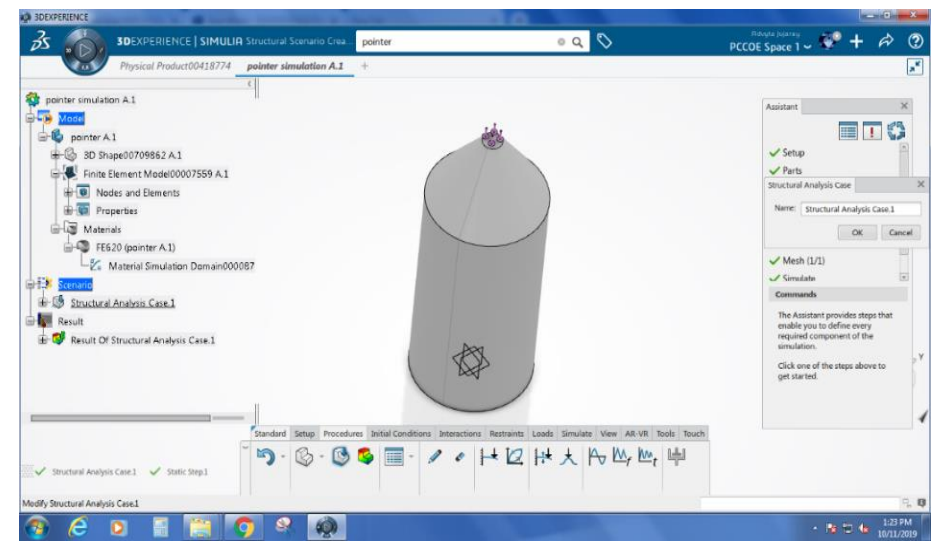

Figure 10 Appling Loads

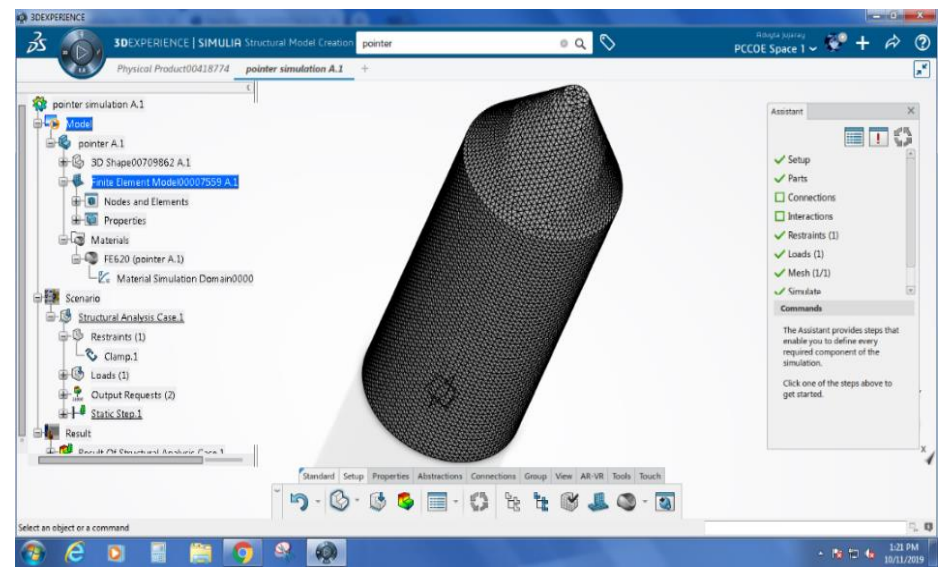

Figure 11 Meshing

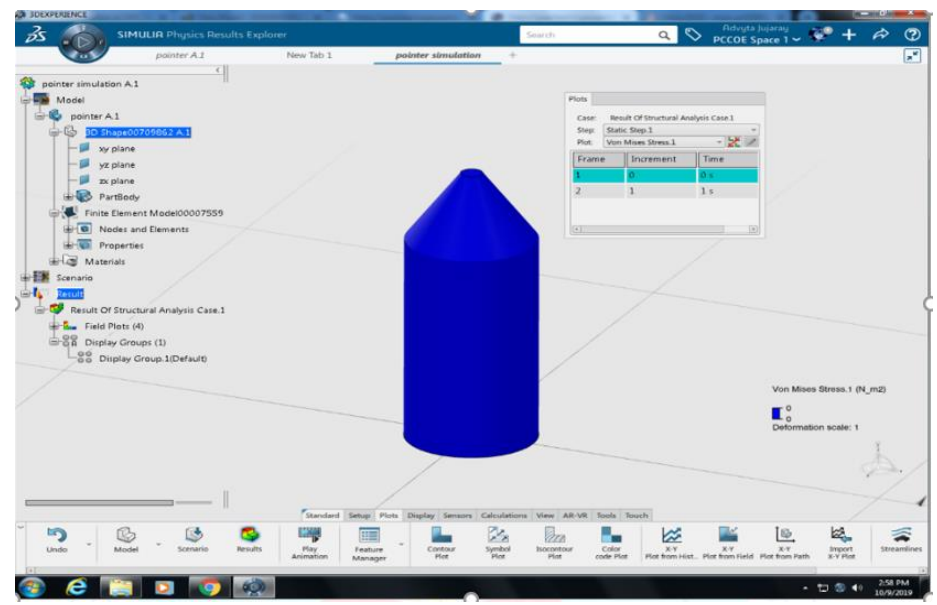

Figure 12 Simulation Results

\section{ACTUAL SCANNING OF THE OBJECT}

Objects were scanned using a 3D scanner- Intel SR real sense 300 . The software used are

- Intel Real Sense

- 3D Sense

- 3DPLM

The scanned data was collected using the Real Sense software. Then the data was imported in 3D Sense Which can save the image. 
The scanner was moved by hand while scanning these objects and as it can be seen clearly in figure the images are missing some parts of the object. If the object is scanned using the proposed mechanism the accuracy of scanning can be improved drastically.
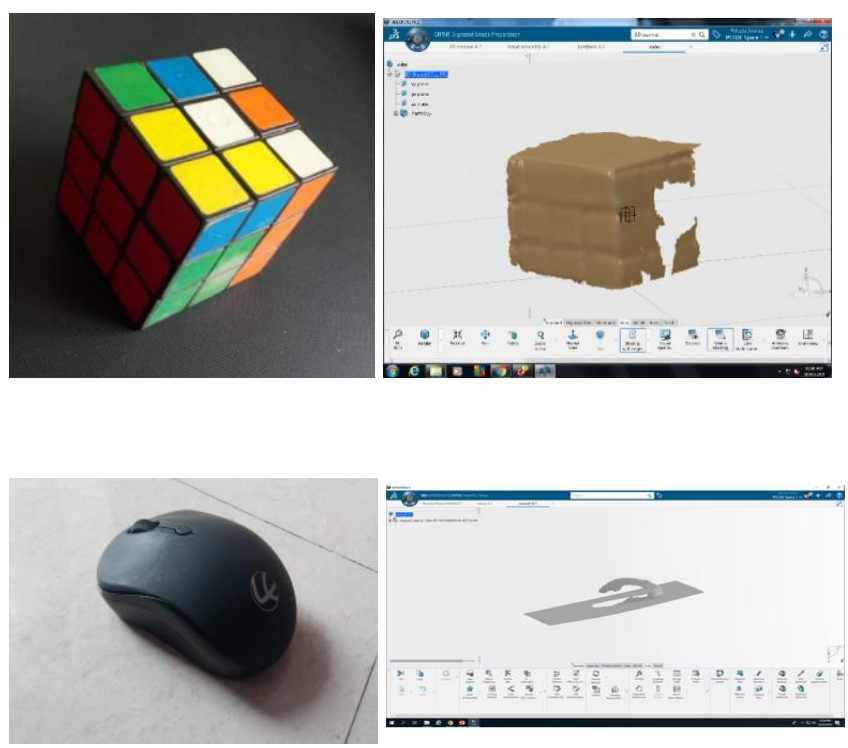

Figure 13 Objects and their scanned images

\section{SIMULATION OF THE SCANNING SYSTEM}

Mechanical system design of 3D Experience software was used to verify the system's working.

According to the size of the object, the upper pointer was be adjusted. Some distance was to be maintained between the scanner and object. This distance can be different for different objects.

When the object is larger in size the scanner is away from its initial position and vise versa.

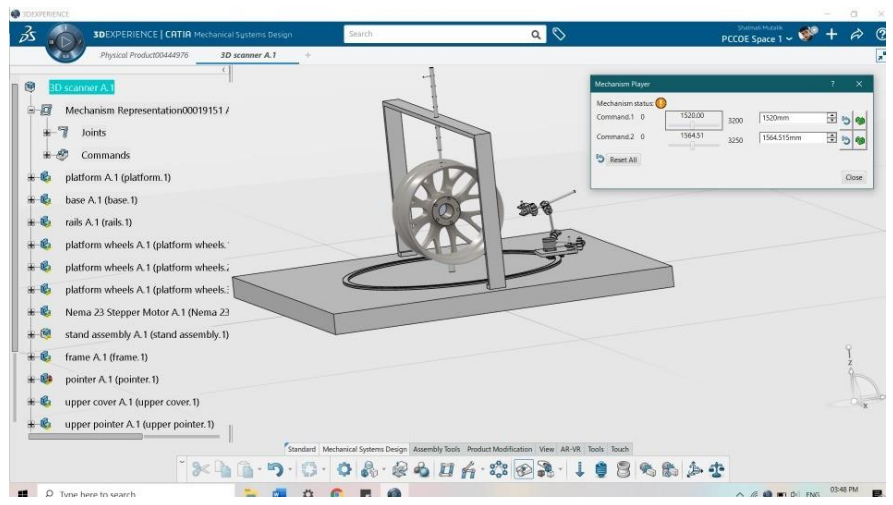

Figure 14 Simulation of BMW wheel

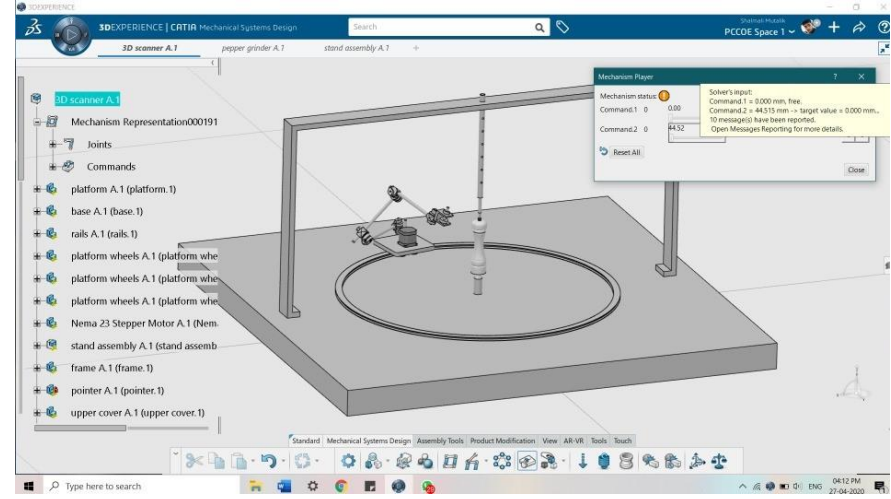

Figure 15 Simulation of pepper crusher

\section{SUMMARY}

1. When scanner motion is given by hand the image is not complete.

2. Data points collected by the scanner are converted into an STL file in 3D Sense. These points can be imported and optimized using the Function Generative Design app of 3D Experience Platform, a Dassault Systeme's platform (3DPLM).

3. Object should be held between two point supports so that maximum area of object can be captured.

4. Analysis was carried out using 'Simulia' apps from 3D Experience software and the resultant was safe design.

\section{REFERENCES}

[1] Michael G. Uva, The Grip Book, Fourth Edition, Elsevier, Pages 297 309.

[2] Jack Anderson, Shooting Movies Without Shooting Yourself in the Foot, Elsevier

\section{Referance Books:}

[3] Bhandari, V.B., Design of Machine Elements, Tata McGraw Hill, 2010

[4] Bhandari, V.B., Machine Design Data Book, Tata McGraw Hill, 2014 Papers from Conference Proceedings:

[5] AlaaAbd-Raheem, Farah AlDeiri, Musa Alyaman, Design of an Automated 3D Scanner, 2018 International Arab Conference on Information Technology (ACIT), Werdanye, Lebanon, 2018

[6] Suchada Rianmora, Kittiphan Nuamchit, Natthakarn Vanasrivilai, Pornpim Tantipiched, Apisit Rammbuth, Applying Scanning Techniques to Create 3d Model, IECON2015-Yokohama, 2015. Papers from Journal or Transactions:

[7] Yu-Cheng Lin, Mao-Jiun J. Wang, Error Analysis of a 3D Scanning System, Digital Human Modelling for Design and Engineering Symposium, 2004

\section{Internet:}

[8] www.https://www.tpa-us.com/curved-rail-system.htm 